\title{
Comparing simultaneously the effects of extra-dyadic and intra-dyadic experiences on relationship outcomes
}

\section{Peter Hilpert, Rebekka Kuhn, Valentina Anderegg \& Guy Bodenmann}

To cite this article: Peter Hilpert, Rebekka Kuhn, Valentina Anderegg \& Guy Bodenmann (2015) Comparing simultaneously the effects of extra-dyadic and intra-dyadic experiences on relationship outcomes, Family Science, 6:1, 129-142, DOI: 10.1080/19424620.2015.1082018

To link to this article: $h$ ttp://dx.doi.org/10.1080/19424620.2015.1082018

曲 Published online: 01 Oct 2015.

Submit your article to this journal $\asymp$

Q View related articles ¿

View Crossmark data $־$

Citing articles: 1 View citing articles 


\title{
Comparing simultaneously the effects of extra-dyadic and intra-dyadic experiences on relationship outcomes
}

\author{
Peter Hilpert ${ }^{\mathrm{a} *}$, Rebekka Kuhn ${ }^{\mathrm{b}}$, Valentina Anderegg ${ }^{\mathrm{b}}$ and Guy Bodenmann ${ }^{\mathrm{b}}$ \\ ${ }^{a}$ Department of Psychiatry and Behavioral Sciences, University of Washington, Seattle, WA, USA; ${ }^{b}$ Department of Psychology, \\ University of Zurich, Zürich, Switzerland
}

(Received 15 September 2014; accepted 22 January 2015)

\begin{abstract}
This study simultaneously examines everyday negative and positive experiences that affect persons either outside of the intimate relationship (extra-dyadic) or within (intra-dyadic). In addition, we investigate whether the partner's responses to each of these experiences mediate the link between experience and relationship outcomes. Altogether, 447 individuals who were currently in a relationship filled out an online questionnaire. Self-report measures included extra- and intra-dyadic everyday experiences of negative and positive events as well as corresponding partner responses and relationship satisfaction. Multigroup path analyses revealed that both negative and positive extra-dyadic experiences affect negative and positive intra-dyadic experiences of women, whereas the effects of positive extra-dyadic experiences had mixed effects for men. Furthermore, the perceived partner responses in each of the four experiences were found to be an important predictor with one exception for men's intra-dyadic positive experiences.
\end{abstract}

Keywords: stress; coping; capitalization; close relationships

'Darling - how was your day?' - Imagine two couples that met after a long day of work. In the first couple, the wife has had very stressful and unpleasant experiences at work, whereas the wife in the second couple has experienced a successful and pleasant day. Research indicates that negative experiences outside of the relationship can spill over into the relationship, increasing the probability of conflict, whereas positive extra-dyadic experiences may have a positive effect on the relationship. But does this mean that stressed couples have fewer positive interactions and couples with positive experiences during the day have fewer negative experiences afterwards? How are these positive and negative experiences related to each other and how do they and their interaction affect relationship outcomes?

According to the intimacy process model (Reis \& Shaver, 1988), the partner's responsiveness is a crucial component in generating relationship satisfaction. Partner B's response to partner A's positive or negative self-disclosure might amplify or buffer partner A's experience. Differentiating four different patterns (positive and negative extra-dyadic as well as positive and negative intradyadic experiences), we assume that the responsive behavior of the partner might matter in all four cases. Research has already separately investigated some of these situations, and thereby often highlighted the importance of partner responsiveness. As Reis (2012) proposes, 'perceived partner responsiveness is a reasonable candidate for a core organizing principle of relationship science' (p. 35). The significance of the partner's responsiveness to the other's stress is well documented in studies that show that dyadic coping is consistently and robustly associated with high relationship satisfaction (see meta-analysis by authors, submitted). On the other hand, the association between high stress, withdrawal from the partner, and subsequent marital tension is also documented (King \& DeLongis, 2014). Unfortunately, the body of research on positive experiences and how the couple interacts in this context is sparse. To sum up, the two aims of the current study are to compare (i) how intra-dyadic experiences mediate the link between extra-dyadic experiences and relationship satisfaction and (ii) how the perceived partner response mediates the link between experiences and relationship outcomes.

\section{Positive and negative extra- and intra-dyadic experiences: spillover}

Research from the few last decades shows that the quality and stability of relationships are associated not only with intra-dyadic experiences but also with contextual or extradyadic experiences. Therefore, we can conceptually differentiate four different experiences: (i) negative extra-dyadic experiences, (ii) positive extra-dyadic experiences, (iii) negative intra-dyadic experiences, and (iv) positive intradyadic experiences. Although studies show that all these experiences contribute significantly to relationship quality and stability, these experiences are mainly studied

*Corresponding author. Email: hilpert@uw.edu 
independently. Since these experiences most likely interact, it might be reasonable to investigate them simultaneously. Caughlin and Huston (2010) argue similarly: 'Knowing there are two separate dimensions [positive and negative] means that it is important to study both simultaneously' (p. 31).

Extra-dyadic experiences can be transmitted into the relationship, which is defined as spillover (Bolger, DeLongis, Kessler, \& Wethington, 1989). For example, Repetti (1989) showed that the daily amount of job stressors for air traffic controllers was associated with their behavior and well-being after work. Spillover effects can be further divided into negative and positive spillover. Negative spillover takes place when a negative, stressful extra-dyadic experience spills into the relationship. Owing to an increase in negative emotions after the event, the behavior in the second, primarily unrelated domain (e.g. the relationship) might be negatively affected. In fact, cross-sectional as well as longitudinal studies show that extra-dyadic stress (e.g. job stress, financial stress, or problems with the family of origin) spills over into relationships and decreases marital satisfaction and stability by negatively affecting couples' communication and increasing conflict interactions (Bodenmann, Ledermann, \& Bradbury, 2007; Bodenmann, Meuwly, Bradbury, Gmelch, \& Ledermann, 2010). Karney and colleagues (Karney, Story, \& Bradbury, 2005) show that newlywed couples that face a lot of stressors at the beginning of their marriage show steeper declines in satisfaction than newlyweds with fewer stressors. In addition, people reporting high work stress exhibit more behaviors like withdrawal, distraction, and lower engagement in relationship-promoting behaviors (Randall \& Bodenmann, 2009; Repetti, 1989; Story \& Repetti, 2006). Finally, Bodenmann et al. (2007) observed that intra-dyadic conflict interactions mediate the association between extra-dyadic stressors and relationship satisfaction.

On the other hand, positive spillover is often conceptualized as perceived gains from the occupation of one role spilling over into another role (Stephens, Franks, \& Atienza, 1997). Edwards and Rothbard (2000) suggest that moods, values, skills, or behaviors spill over and positively affect another domain. In our study, we hypothesize that the individual experiences a positive extra-dyadic event, which then spills over into the relationship. Several studies show that positive experiences at work have a positive effect on the family domain (e.g. Edwards \& Rothbard, 2000; Greenhaus \& Powell, 2006; Hanson, Hammer, \& Colton, 2006; Wayne, Musisca, \& Fleeson, 2004). Miner, Glomb, and Hulin (2005) reported that employees were in a better momentary mood when they had experienced positive work events. In addition, the quality of family life can be enhanced by positive spillover effects (Wayne et al., 2004). However, to our knowledge, there is no study examining how positive experiences that occurred outside of the relationship (e.g. leisure, social interactions, children) spill over into intimate relationships and whether these intra-dyadic positive experiences function as a mediator between extra-dyadic positive events and relationship satisfaction. To sum up, in our conceptual model we assume that intra-dyadic experiences mediate the link between extra-dyadic experiences and relationship satisfaction (see Figure 1).

\section{Partner's response to extra- and intra-dyadic experiences}

Although examining spillover effects of extra-dyadic on intra-dyadic experiences is informative, it ignores the assumption that these spillover effects also depend on the perception of the partner's subsequent response (see intimacy process model, Reis \& Shaver, 1988). Perceived partner responsive behavior is the degree to which one feels understood, supported, and cared for through the partner's reaction (e.g. Maisel, Gable, \& Strachman, 2008; Reis \& Shaver, 1988) and reflects how sensitively and appropriately a partner responds to the other's needs (Clark \& Monin, 2006; Mikulincer \& Shaver, 2003). Depending on the partner's behavior, the momentary experience caused by the event might change.

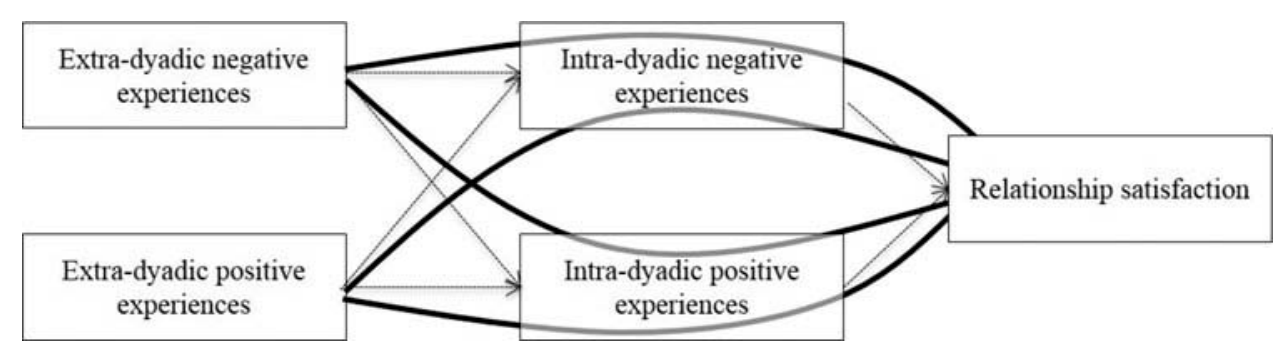

Figure 1. Mediation effects: intra-dyadic experiences mediate the link between extra-dyadic experiences and relationship satisfaction (bold paths). 
Because all four types of events described above cause different stressful or positive experiences, four respective responses can systematically be defined. For three types of experiences, the responsive behavior has already been described in the literature (1. dyadic coping behavior for extra-dyadic stress; 2 . conflict interaction during intra-dyadic stress; and 3. capitalization responses regarding extra-dyadic positive experiences). Capitalizing as a specific partner response to intra-dyadic positive experiences has not been described yet. All four partner responses are briefly described below.

\section{Response to extra-dyadic negative experiences}

Considerable evidence indicates that negative extra-dyadic experiences increase negative emotions that can spill over into the intimate relationship (e.g. Repetti, 1989). Whether the stressor can be handled depends to a great extent on the partner's supportive response such as showing understanding for and empathizing with the other partner's worries, problems, or pain (Bodenmann, 2005). This kind of response (i.e. dyadic coping) results in feelings of closeness and intimacy for both partners. A successful stress-coping process is a central predictor for relationship satisfaction and stability (e.g. Bodenmann \& Cina, 2006; Bodenmann, Pihet, \& Kayser, 2006; Herzberg, 2013; Papp \& Witt, 2010; Sullivan, Pasch, Johnson, \& Bradbury, 2010). Furthermore, findings show that the partner's response mediates the link between extra-dyadic negative experiences and relationship satisfaction (Bodenmann et al., 2010), but there is no study thus far examining whether the partner's response also mediates the association between extra- and intra-dyadic coping. Nevertheless, the Systemic-Transactional Model (Bodenmann, 1997) suggests this mechanism.

\section{Response to intra-dyadic negative experiences (i.e conflict)}

Intra-dyadic negative experiences can be defined as conflicts occurring from differences in goals, attitudes, needs, and desires (Randall \& Bodenmann, 2009). According to this definition, all couples have conflicts, but satisfied and unsatisfied couples differ in the way they solve their disputes. Whereas ineffective conflict interactions during relationship distress are associated with lower marital satisfaction, constructive conflict interactions lead to compromises that promote relationship satisfaction (Cramer, 2006). Similar to the dyadic coping construct, the process of whether one feels understood and validated during a conflict depends on the perceived partner responsiveness. Studies have therefore described the behavior during the conflict resolution process as a mediator between the actual conflict and relationship satisfaction (Kurdeck, 1994; Marchand, 2004; Sierau \& Herzberg, 2012).

\section{Response to extra-dyadic positive experiences (i.e capitalization)}

During the last decade, several studies focused on pleasant events (e.g. Gable, Gosnell, Maisel, \& Strachman, 2012; Gable \& Reis, 2010; Gable, Reis, Impett, \& Asher, 2004). Sharing good news and positive experiences with the partner or a friend is a process called capitalization (Langston, 1994), whereby people maximize the effect of a positive event by telling others about it. However, the response of the listener (hereafter, 'capitalization response') plays an important role in that process and has effects on the relationship between the speaker and the listener. Four different capitalization reactions have been described by Gable et al. (2004): active-constructive, active-destructive, passive-constructive, and passivedestructive. Out of these four reactions, only active-constructive responses are an adaptive form of partner responsiveness. If the partner is perceived to respond actively and constructively to his or her spouse sharing the experience of a positive event, higher relationship well-being, including intimacy or daily marital satisfaction, has been reported (Gable et al., 2004). Moreover, it was found that romantic relationships showed higher daily positive activities between partners, and therefore intra-dyadic positive events, when displaying supportive capitalization responses (Gable \& Reis, 2006). Thus, a partner being able to react positively to capitalization attempts might enhance the positive spillover effect of extra-dyadic on intra-dyadic experiences. A capitalization response would thus be a mediator of the spillover.

\section{Response to intra-dyadic positive experiences}

In contrast to the aforementioned type of extra-dyadic positive response (i.e. capitalization response), where a person shares new information with a friend or the spouse, capitalization for intra-dyadic events is different. In general, couples experience a fair amount of positive events that happen inside of the relationship (e.g. being intimate, enjoying time together; Hilpert, Bodenmann, Nussbeck, \& Bradbury, 2013), but telling the partner about it cannot surprise the partner because they have experienced it together. Nevertheless, based on the intimacy process model (Reis \& Shaver, 1988), it is still reasonable to assume that expressing and reflecting on the wonderful time with the partner, and getting a supportive response from the partner, might have positive effects on relationship outcomes. For example, in a study by Graber, Laurenceau, Miga, Chango, and Coan (2011), feelings of intimacy and relationship satisfaction 


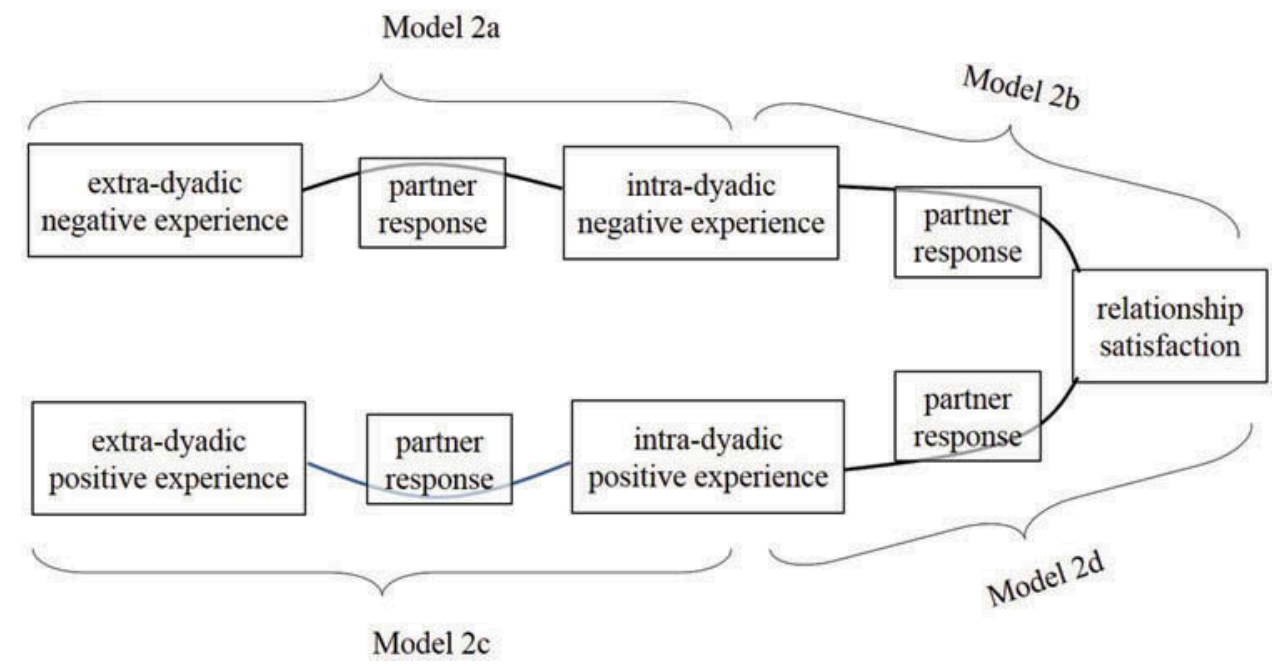

Figure 2. This model builds on the prior model, where we assumed that extra-dyadic experiences predict intra-dyadic experiences, which in turn predict relationship satisfaction. In this model, we additionally assumed that between these associations, partner response is a crucial mediator (see bold paths).

were found to be more intense when newlywed couples reflected on positive feelings toward their partner. In sum, in our conceptual model we assume that the perceived responsive behavior of the partner mediates both the link between extra-dyadic experiences on intra-dyadic experiences and the link between intra-dyadic experiences and relationship satisfaction (see Figure 2).

\section{Hypotheses}

We have two major aims in the current study. First, we examine how negative and positive extra-dyadic experiences spill over into negative and positive intra-dyadic experiences, which in turn may predict relationship satisfaction (mediation mechanism, see Figure 1). We therefore start by drawing upon the findings by Bodenmann et al. (2007) that negative intra-dyadic experiences mediate the association between negative extra-dyadic experiences and relationship satisfaction (i.e. negative spillover mechanism) and seek to replicate this finding (H1a). In addition, we assume to find a similar picture for positive experiences and hypothesize that intra-dyadic positive experiences mediate the association between extra-dyadic positive experiences and relationship satisfaction (i.e. positive spillover mechanism; H1b). Finally, we predict crossed effects: negative intra-dyadic experiences mediate the association between positive extra-dyadic experiences and relationship satisfaction (H1c), and vice versa (H1d).

Our second aim is to test whether perceived partner responses act as a mediator for each of the four different experiences (see Figure 2). In more detail, in our second set of hypotheses we assume that each of the four partner responses play a mediating role in the process of how extra-dyadic experiences affect intra-dyadic experiences and how intra-dyadic experiences affect relationship satisfaction. We state that the perceived partner response (i.e. dyadic coping) after negative extra-dyadic experiences mediates the association between negative extra-dyadic experiences and negative intra-dyadic experiences (H2a); perceived partner response (i.e. conflict resolution) after negative intra-dyadic experiences mediates the association between negative intra-dyadic experiences and relationship satisfaction (H2b); perceived partner response (i.e. capitalization response) after positive extra-dyadic experiences mediates the association between positive extradyadic experiences and positive intra-dyadic experiences $(\mathrm{H} 2 \mathrm{c})$; and finally, perceived partner response (i.e. internal capitalization response) after positive intra-dyadic experiences mediates the association between positive intra-dyadic experiences and relationship satisfaction $(\mathrm{H} 2 \mathrm{~d})$.

\section{Method \\ Participants}

In total, 455 participants (79 men, 376 women) participated in the study. Men's mean age was 35.3 years $(S D=2.4)$, and women's mean age was 30.3 years $(S D=1.9)$. Forty per cent of men and $28.3 \%$ of women were married. Men who indicated being married were on average 14.4 years $(S D=10.5)$ in their current marriage and married women 8.6 years $(S D=8.2)$. The average relationship duration of non-married participants was lower with 3.9 years $(S D=3.2)$ for men and 3.9 years $(S D=3.1)$ for women. The average number of children across the whole sample was $1.3(S D=0.5)$. Regarding their years of education, men and women were quite 
similar, with men having 17.1 years $(S D=4.2)$ and women 17.4 years $(S D=3.7)$ of education.

\section{Procedure}

Participants were recruited via email and different online forums. Initially, 579 persons started filling out the questionnaires and 455 of them filled them out completely. To avoid data confounding with dependent data, eight women had to be excluded, as their partner had also filled out the questionnaires. The final sample consisted of 447 participants. As a requirement, participants needed an internet connection and had to have been in a relationship for at least 1 year. Furthermore, participants received information about the study and had to sign a participation agreement before they could start with the study. With this, the ethical guidelines were fulfilled according to the standards. The questionnaires were filled out online and secured by an individual code to guarantee anonymity and confidentiality. The mean duration time of answering the questions was about 1 hour.

The questionnaires were presented in the following way. Participants received questions about the four events and the associated partner response in a stepwise procedure. After explaining and defining the events, participants filled out questions about the first event (negative extradyadic experiences), followed by questions about how the partner would respond in this specific situation. In this way we made sure that the partner's response was clearly linked to the event. Next, participants received questions about the second event (positive extra-dyadic experiences), again followed by questions about the partner's response. This procedure was repeated for negative and positive intra-dyadic experiences and responses.

\section{Measures}

Demographic variables

Participants provided information on their age, sex, marital status, relationship duration, relationship quality, type of residence, number of children, religion, education, profession, and employment.

\section{Experienced events (adapted version of GLS)}

All of the four experiences were measured on the basis of the General Level of Stress (GLS) questionnaire (Bodenmann, 2000). In general, the GLS differentiates two subtypes: extra-dyadic negative experiences and intra-dyadic negative experiences that are rated in their intensity on a Likert scale ranging from $1=$ 'not at all' to $4=$ 'very severe', with higher scores indicating higher levels of stress. The GLS has been widely used, demonstrates good validity, and has good psychometric properties (Bodenmann, 2000).

Extra-dyadic negative experiences. In total, nine areas of potential relationship external stress were assessed, namely job/education, social contacts, leisure time, children, family of origin, living situation, financial situation, daily hassles, and household (Instruction: Please specify how stressful the following situations were for you during the last 6 months: e.g. Job/Education [hectic pace, deadline pressure, high demands, being unchallenged, lacking acknowledgement and career opportunities, etc.]; or Financial Situation [debts, lack of money, no raise, financial losses, etc.]). External stressful experiences had an internal consistency (Cronbach's alpha) of $\alpha=.76$ for men and $\alpha=.80$ for women across all nine domains.

Intra-dyadic negative experiences. In order to assess intradyadic negative experiences, participants rated the intensity of different internal stressors, namely difference in opinion, different attitudes concerning relationship and life, disturbing habits, difficult personality, insufficient behavior, strong restrictions through the relationship, too much distance from the partner, unsatisfactory distribution of duties and responsibilities, and neglect by the partner (Instruction: Please specify how stressful the following situations were for you during the last 6 months: e.g. Difference in opinion [conflicts, disputations]; or disturbing habits [manners, carelessness, inattentiveness, etc.]). Internal validity was quite high with $\alpha=.93$ for men and $\alpha=.88$ for women.

Based on the GLS, we developed a new questionnaire, mirroring the two GLS subscales as closely as possible, but assessing positive experiences. As for the negative experiences, we measured extra-dyadic and intra-dyadic positive experiences on a Likert scale ranging from $1=$ 'not at all' to $4=$ 'very strong'.

Extra-dyadic positive experiences. To assess the extradyadic positive experiences, we asked for the same areas/domains as for the extra-dyadic negative experiences (job/education, social contacts, leisure time, etc.). However, this time we asked participants to rate the intensity of positive experiences (Instruction: Please specify how positive you have experienced the following situations during the last 6 months: e.g. Job/Education [exciting challenge, praise, success, fulfillment, etc.)]; or Financial Situation [share profit or lottery win, unloaded financial situation, wage increase, etc.]). The internal consistency for extra-dyadic positive experiences was $\alpha=.84$ for men and $\alpha=.75$ for women.

Intra-dyadic positive experiences. In order to assess the intra-dyadic positive experiences, we could not use the same events as for the intra-dyadic negative experiences 
because asking for positive habits instead of negative ones, for example, does not sufficiently characterize positive experiences in the intimate relationship. Nine positive events, namely attention of partner, surprises, presents, communication, pleasant activities, emotional self-disclosure, tenderness, sexuality, and spirituality, were assessed (Instruction: Please specify how positive you have experienced the following situations during the last 6 months: e.g. Emotional Self-Disclosure [shares his/her most important goals, needs, future plans, desires and fears, etc.]; or Spirituality [Discussions about religion, believes, philosophy, life plans, meditation, etc.]). Internal consistency ranged from $\alpha=.90$ for men to $\alpha=.89$ for women.

\section{Perceived partner responses to the different experiences}

In order to assess perceived partner responses for the four different experiences, we developed two new orthogonal scales for negative and positive experiences, which were then both used twice (e.g. ratings of the response to positive events were applied after the scales for the positive external as well as internal experiences). Developing these new scales was as follows. In order to assess the partner's response to negative experiences, we measured three aspects of supportive and constructive partner reactions based on the established dyadic coping inventory (DCI; Bodenmann, 2008). To assess the response of the partner to positive experiences, we measured three aspects of active-constructive behavior based on the findings on capitalization responses by Gable and colleagues (2004). Each of the perceived partner responses was rated directly after the corresponding experience. Participants indicated the frequency of the response on a Likert scale ranging from 1 = 'never' to 4 = 'often', with higher scores representing more adaptive partner responses.

Perceived response to negative experiences. In order to assess the perceived partner response after experiencing extra- or intra-dyadic negative events, participants were asked to rate the frequency of their partner's problemfocused, emotion-focused, and helpful response (My partner assists with support and advice; My partner responds to me and my feelings; My partner responds to my (relationship) stress in a helpful way). These questions were asked twice, directly after each of the corresponding negative events. Internal consistency ranged from $\alpha=.84$ for men to $\alpha=.85$ for women for extra-dyadic negative experiences and ranged from $\alpha=.88$ for men and $\alpha=.88$ women for intra-dyadic negative experiences.

Perceived response to positive experiences. Participants were asked to rate the frequency of the partner's active and constructive response in order to assess the perceived partner response for extra- and intra-dyadic positive experiences (My partner is happy for me; My partner responds to me and my feelings; My partner responds to my positive everyday/relationship experience in a helpful way). These questions were asked directly after each of the corresponding positive events. Internal consistency ranged from $\alpha=.92$ for men to $\alpha=.88$ for women for extradyadic negative experiences and ranged from $\alpha=.87$ for men to $\alpha=.83$ for women for intra-dyadic positive experiences.

\section{Marital satisfaction (CSI)}

Relationship satisfaction was assessed with the 16-item format of the Couple Satisfaction Index (Funk \& Rogge, 2007). First, on a 7-point Likert scale ranging from $0=$ 'extremely unhappy' to $6=$ 'perfect', participants indicated their general degree of happiness with the relationship. The other 15 items (e.g. I have a warm and comfortable relationship with my partner) specified relationship issues and were rated on a 6-point Likert scale. Internal validity was $\alpha=.94$ for men and $\alpha=.97$ for women.

\section{Statistical analyses}

All hypotheses were tested in a multigroup path analytical model. Such an approach allows for simultaneous testing of gender differences with respect to model parameters. We used a stepwise procedure to test the aforementioned hypotheses. First, we computed a saturated model (all model parameters are freely estimated). Second, we used a stepwise procedure to test for gender effects by restricting the paths for men and women to be equal. If the model fits the data, the restriction was kept in. If not, the restriction was revoked. Then, the next path was restricted and the process was continued until all paths were tested and the most parsimonious model found. In our final model, one path was restricted between groups (men/women).

In the first set of hypotheses, we aimed to test whether intra-dyadic experiences mediate the associations between extra-dyadic experiences and relationship satisfaction (H1a-H1c; see Figure 1). In order to test the second set of hypotheses, we aimed to test four explanatory mechanisms (mediators) for the aforementioned model (see Figure 2). Owing to sample size restrictions and model complexity, we computed each mediator analysis in a separate model $(\mathrm{H} 2 \mathrm{a}-\mathrm{H} 2 \mathrm{~d})$.

We relied on common fit indices for structural equation modeling (Schermelleh-Engel, Moosbrugger, \& Müller, 2003). Descriptive statistics were computed using SPSS 22.0 and the path analytical models were computed using the R package lavaan (version 0.5-16; Rosseel, 2012). The full information maximum likelihood estimator (FIML) with bootstrap was used. 


\section{Results}

\section{Descriptive statistics}

Table 1 shows the means and $S D$ among the study variables. Men and women showed significant differences in the report of how intense their negative and positive experiences were. Women almost always reported more intense negative as well as positive experiences. For perceived partner responsiveness, men and women did not show any significant differences except for the response after positive intra-dyadic experience. Consistent with most studies, relationship satisfaction was high for both men and women, with no significant differences for gen$\operatorname{der}\left(M_{\text {Men }}=4.42, M_{\text {Women }}=4.36\right.$, range 1-5).

Table 2 presents the inter-correlations for all study variables. Results showed significant correlations between negative and positive extra-dyadic experiences for women $(r=-.28, p=.000)$, whereas negative and positive experiences were unrelated for men. This finding points to

Table 1. Means, standard deviations, and T-tests for the different experiences, partner responses, and relationship satisfaction.

\begin{tabular}{lcccc}
\hline & Men & & Women & \multirow{2}{*}{$t$ test } \\
\cline { 2 - 2 } Variable & $M(S D)$ & & $M(S D)$ & $p$ \\
\hline Experience & & & \\
Extra-dyadic negative & $1.92(0.38)$ & $2.22(0.52)$ & & .000 \\
Intra-dyadic negative & $1.83(0.58)$ & $2.02(0.70)$ & .021 \\
Extra-dyadic positive & $3.00(0.59)$ & $3.16(0.48)$ & .020 \\
$\quad$ Intra-dyadic positive & $3.18(0.67)$ & $3.31(0.66)$ & .129 \\
Partner response & & & \\
Extra-dyadic negative & $3.38(0.61)$ & $3.33(0.68)$ & .573 \\
Intra-dyadic negative & $3.21(0.72)$ & $3.06(0.70)$ & .201 \\
Extra-dyadic positive & $3.56(0.63)$ & $3.60(0.59)$ & .612 \\
$\quad$ Intra-dyadic positive & $3.48(0.62)$ & $3.72(0.45)$ & .006 \\
Relationship satisfaction & $4.42(0.75)$ & $4.36(1.00)$ & .540 \\
\hline
\end{tabular}

gender differences on a quite basic level. Less surprisingly, results showed that positive and negative intra-dyadic events were highly correlated $\left(r_{\text {men }}=0.60, p=.000 ; r_{\text {women }}=0.60\right.$, $p=.000)$. In relation to partner responses, results indicated similar effects for women and men: perceived partner responses after negative and positive experiences correlated highly $\left(r_{\text {men }}=0.65, p=.000 ; r_{\text {women }}=0.73, p=.000\right)$. Similarly, we found that partners' responses to negative and positive intra-dyadic experiences were also correlated $\left(r_{\text {women }}=0.50, p=.000 ; r_{\text {women }}=0.54, p=.000\right)$. Finally, all study variables were significantly correlated with relationship satisfaction except for men's extra-dyadic negative and positive experiences.

\section{Spillover effects of extra-dyadic experiences on intra- dyadic outcomes}

\section{Experiences in the four events}

In order to test the first set of hypotheses, we tested whether extra-dyadic experiences spill over into intimate relationships. The multigroup path analytical model fit the data well $\left(\chi^{2}=3.8 ; d=20 ; p=.000 ; \chi^{2} / d f=0.17\right.$; $\mathrm{CFI}=1.000 ;$ TLI $=1.013$; RMSEA $=.000)$.

In the first hypothesis $(\mathrm{H} 1 \mathrm{a})$, we aimed to replicate whether intra-dyadic negative experiences mediate the association between extra-dyadic negative experiences and relationship satisfaction. As can be seen in Table 3, we found a full mediation for men and women and no significant gender differences $(\beta=-.51, p<.001)$, which replicates the finding of Bodenmann et al. (2007). Thus, one can conclude that extra-dyadic negative experiences do spill over into relationships by increasing intra-dyadic conflicts, which then in turn decrease relationship satisfaction.

Table 2. Correlation matrix of the different experiences for men and women.

\begin{tabular}{|c|c|c|c|c|c|c|c|c|c|}
\hline & \multicolumn{4}{|c|}{ Experience } & \multicolumn{4}{|c|}{ Perceived responsiveness } & \multirow{2}{*}{$\frac{\mathrm{RS}}{9}$} \\
\hline & 1 & 2 & 3 & 4 & 5 & 6 & 7 & 8 & \\
\hline \multicolumn{10}{|l|}{ Experience } \\
\hline Extra-dyadic negative (1) & - & .43 & -.28 & -.19 & -.31 & -.32 & -.27 & -.10 & -.29 \\
\hline Intra-dyadic negative (2) & .35 & - & -.16 & -.60 & -.62 & -.66 & -.55 & -.47 & -.81 \\
\hline Extra-dyadic positive (3) & -.04 & -.15 & - & .18 & .24 & .18 & .14 & .14 & .18 \\
\hline Intra-dyadic positive (4) & -.17 & -.60 & .30 & - & .54 & .57 & .47 & .56 & .70 \\
\hline \multicolumn{10}{|l|}{ Partner response } \\
\hline Extra-dyadic negative (5) & -.10 & -.47 & .09 & .55 & - & .66 & .65 & .58 & .67 \\
\hline Intra-dyadic negative (6) & -.21 & -.59 & .25 & .48 & .47 & - & .56 & .50 & .65 \\
\hline Extra-dyadic positive (7) & -.04 & -.44 & .17 & .56 & .73 & .35 & - & .65 & .63 \\
\hline Intra-dyadic positive (8) & .03 & -.42 & .29 & .58 & .60 & .54 & .73 & - & .57 \\
\hline Relationship satisfaction (9) & -.22 & -.79 & .13 & .64 & .51 & .66 & .50 & .40 & - \\
\hline
\end{tabular}

Note: Intercorrelations for women are above the diagonal, intercorrelations for men below: $\mathrm{RS}=$ Relationship satisfaction, significance $(p<.05)$ is indicated by bold numbers. 
Table 3. Direct effects, indirect effects, and total indirect effects of the path analytical multigroup mediation model for the different experiences for men and women.

\begin{tabular}{|c|c|c|c|c|c|}
\hline Direct effects & Lower $2.5 \%$ & Estimate & Upper $2.5 \%$ & s.e. & $p$ \\
\hline $\mathrm{M} \& \mathrm{~W}: \mathrm{EN} \rightarrow \mathrm{RS}$ & -0.039 & 0.099 & 0.237 & 0.071 & 0.160 \\
\hline $\mathrm{M} \& \mathrm{~W}: \mathrm{EP} \rightarrow \mathrm{RS}$ & -0.088 & 0.035 & 0.157 & 0.063 & 0.579 \\
\hline $\mathrm{M} \& \mathrm{~W}: \mathrm{EN} \rightarrow \mathrm{NI}$ & 0.408 & 0.561 & 0.715 & 0.079 & 0.000 \\
\hline $\mathrm{M} \& \mathrm{~W}: \mathrm{IN} \rightarrow \mathrm{RS}$ & -1.034 & -0.910 & -0.786 & 0.063 & 0.000 \\
\hline $\mathrm{M} \& W: \mathrm{EP} \rightarrow \mathrm{IP}$ & 0.090 & 0.238 & 0.385 & 0.075 & 0.002 \\
\hline $\mathrm{M}: \mathrm{PI} \rightarrow \mathrm{RS}$ & 0.051 & 0.238 & 0.425 & 0.095 & 0.013 \\
\hline $\mathrm{W}: \mathrm{PI} \rightarrow \mathrm{RS}$ & 0.407 & 0.530 & 0.654 & 0.063 & 0.000 \\
\hline $\mathrm{M} \& \mathrm{~W}: \mathrm{NE} \rightarrow \mathrm{PI}$ & -0.362 & -0.199 & -0.037 & 0.083 & 0.016 \\
\hline $\mathrm{M} \& \mathrm{~W}: \mathrm{PE} \rightarrow \mathrm{NI}$ & -0.209 & -0.067 & 0.075 & 0.072 & 0.353 \\
\hline \multicolumn{6}{|l|}{ Indirect effects } \\
\hline $\mathrm{M} \& \mathrm{~W}: \mathrm{EN} \rightarrow \mathrm{IN} \rightarrow \mathrm{RS}$ & -0.67 & -0.511 & -0.352 & 0.081 & 0.000 \\
\hline $\mathrm{M}: \mathrm{EP} \rightarrow \mathrm{IP} \rightarrow \mathrm{RS}$ & 0.000 & 0.057 & 0.114 & 0.029 & 0.052 \\
\hline $\mathrm{W}: \mathrm{EP} \rightarrow \mathrm{IP} \rightarrow \mathrm{RS}$ & 0.044 & 0.126 & 0.208 & 0.042 & 0.003 \\
\hline $\mathrm{M}: \mathrm{EN} \rightarrow \mathrm{IP} \rightarrow \mathrm{RS}$ & -0.101 & -0.047 & 0.006 & 0.027 & 0.082 \\
\hline $\mathrm{W}: \mathrm{EN} \rightarrow \mathrm{IP} \rightarrow \mathrm{RS}$ & -0.198 & -0.106 & -0.013 & 0.047 & 0.025 \\
\hline $\mathrm{M} \& \mathrm{~W}: \mathrm{EP} \rightarrow \mathrm{IN} \rightarrow \mathrm{RS}$ & -0.068 & 0.061 & 0.190 & 0.066 & 0.353 \\
\hline M: Total indirect effect & -0.694 & -0.441 & -0.187 & 0.129 & 0.001 \\
\hline W: Total indirect effect & -0.732 & -0.430 & -0.127 & 0.154 & 0.005 \\
\hline
\end{tabular}

Note: $\mathrm{M}=$ men; $\mathrm{W}=$ women; $\mathrm{M} \& \mathrm{~W}=$ men and women; $\mathrm{EN}=$ Extra-dyadic negative experiences; $\mathrm{IN}=$ Intra-dyadic negative experiences; $\mathrm{EP}=\mathrm{Extra}-$ dyadic positive experiences; IP = Intra-dyadic positive experiences; RS = Relationship satisfaction; lower and upper $2.5 \%$ indicate the boundaries of the $95 \%$ confidence interval; s.e. $=$ standard error; $p=$ significance level. Unstandardized results are depicted.

In the second hypothesis (H1b), we hypothesized to find a similar spillover mechanism for positive experiences. Indeed, the results show a similar spillover mechanism for women: the intra-dyadic positive experiences clearly mediate the association between extradyadic positive experiences and relationship satisfaction $(\beta=.13, p=.003)$, indicating that the extra-dyadic positive experience actually spills over. However, we find only a marginal significant mediation effect for men $(\beta=.06, p=.052)$. But even if we might find a significant effect by having an equally large sample size for men as for women, an additional test showed that the spillover mechanism (i.e. the indirect effect) is significantly lower for men compared to that for women $(\Delta \beta=.07, p=.000)$.

In the third hypothesis (H1c), we expected to find effects between positive and negative experiences. First, results show that extra-dyadic negative experiences are negatively associated with intra-dyadic positive experiences for men and women equally $(\beta=-.36, p=.016)$. This indicates that negative experiences not only increase intra-dyadic negative experiences, but also simultaneously reduce positive interaction within couples.

For extra-dyadic positive experiences (H1d), however, no direct effect could be found on intra-dyadic negative experiences, indicating that these extra-dyadic positive experiences do not directly affect intra-dyadic negative experiences. Inspecting the indirect effects, we only find a significant effect for women: extradyadic negative experiences reduce relationship satisfaction by affecting intra-dyadic positive experiences $(\beta=.11, p=.025)$, which is not the case for men $(\beta=-.05, p=.082)$. No significant indirect effects were found from extra-dyadic positive experiences to intra-dyadic negative experiences to relationship satisfaction.

\section{Perceived partner response as mediator}

In order to extend the understanding of how intra-dyadic experiences mediate the association between extra-dyadic experiences and relationship satisfaction, in our second set of hypotheses we assumed that the perceived partner response would be a good candidate for an explanatory mechanism between the above-mentioned variables (see Figure 2). Because of sample size restriction, we tested each mediation in an individual model.

\section{Perceived response in extra-dyadic negative experiences (H2a)}

The multigroup path analytical model fit the data well $\left(\chi^{2}=2.4 ; d=3 ; p=.44 ; \chi^{2} / d f=0.78 ;\right.$ CFI $=1.000$; $\mathrm{TLI}=1.006$; RMSEA $=.000$ ). As many studies show, we hypothesized that the perceived partner response is very crucial for relationships in times of extra-dyadic negative 
Table 4. Direct effects, total direct effects, and indirect effects of the path analytical multigroup mediation model for the mediation models of negative experiences and relationship satisfaction (Hypotheses 2a \& 2b).

\begin{tabular}{|c|c|c|c|c|c|}
\hline & Lower $2.5 \%$ & Estimate & Upper $2.5 \%$ & s.e. & $p$ \\
\hline \multicolumn{6}{|c|}{ Extra-dyadic negative experiences } \\
\hline \multicolumn{6}{|c|}{ Direct effects } \\
\hline M\&W: EN $\rightarrow$ PrEN & -0.531 & -0.395 & -0.258 & 0.070 & 0.000 \\
\hline $\mathrm{M} \& \mathrm{~W}: \operatorname{PrEN} \rightarrow \mathrm{IN}$ & -0.614 & -0.530 & -0.445 & 0.043 & 0.000 \\
\hline $\mathrm{M} \& \mathrm{~W}: \mathrm{EN} \rightarrow \mathrm{IN}$ & 0.238 & 0.354 & 0.470 & 0.059 & 0.000 \\
\hline M\&W: Total direct effect & 0.434 & 0.563 & 0.692 & 0.066 & 0.000 \\
\hline \multicolumn{6}{|l|}{ Indirect effects } \\
\hline M\&W: Indirect effect & 0.129 & 0.209 & 0.289 & 0.041 & 0.000 \\
\hline \multicolumn{6}{|c|}{ Intra-dyadic negative experiences } \\
\hline \multicolumn{6}{|c|}{ Direct effects } \\
\hline M\&W: IN $\rightarrow$ PrIN & -0.850 & -0.743 & -0.637 & 0.054 & 0.000 \\
\hline M\&W: PrIN $\rightarrow$ RS & 0.205 & 0.329 & 0.452 & 0.063 & 0.000 \\
\hline $\mathrm{M} \& \mathrm{~W}: \mathrm{IN} \rightarrow \mathrm{RS}$ & -1.017 & -0.888 & -0.759 & 0.066 & 0.000 \\
\hline M\&W: Total direct effect & -1.219 & -1.133 & -1.046 & 0.044 & 0.000 \\
\hline \multicolumn{6}{|l|}{ Indirect effects } \\
\hline M\&W: Indirect effect & -0.345 & -0.244 & -0.143 & 0.052 & 0.000 \\
\hline
\end{tabular}

Notes: $\mathrm{M} \& \mathrm{~W}=$ men and women; $\mathrm{EN}=$ extra-dyadic negative experience; $\mathrm{PrEN}=$ partner response to extra-dyadic negative experience; $\mathrm{IN}=$ intra-dyadic negative experience; PrIN = partner response to intra-dyadic negative experience; RS = relationship satisfaction; lower and upper $2.5 \%$ indicate the boundaries of the $95 \%$ confidence interval, s.e. $=$ standard error; $p=$ significance level. Unstandardized results are depicted.

experiences. As expected, we found a significant indirect effect and no gender differences $(\beta=.21, p=.000$, see Table 4).

\section{Perceived response in intra-dyadic negative experiences ( $\mathrm{H} 2 \mathrm{~b}$ )}

For hypothesis $\mathrm{H} 2 \mathrm{~b}$, the model proved a good model fit as well $\left(\chi^{2}=3.2 ; d=3 ; p=.36 ; \chi^{2} / d f=0.11 ; \mathrm{CFI}=1.000\right.$; TLI $=0.999$; RMSEA $=.018)$. We assumed that the perceived partner response during conflict mediates the association between intra-dyadic conflicts and relationship satisfaction. Results support this assumption for both men and women $(\beta=-.24, p=.000$, see Table 4$)$.

\section{Perceived response in extra-dyadic positive experiences ( $\mathrm{H} 2 \mathrm{c}$ )}

The multigroup path analytical model for hypothesis $\mathrm{H} 2 \mathrm{c}$ fit the data well $\left(\chi^{2}=0.2 ; d=3 ; p=.97 ; \chi^{2} / d f=0.07\right.$; $\mathrm{CFI}=1.000$; TLI $=1.053$; RMSEA $=.000$ ). We assumed we would find similar indirect effects for positive experiences as for negative experiences: the perceived capitalization response mediates the association between extra- and intradyadic positive experiences. Results support this assumption for both men and women $(\beta=.09, p=.012$, see Table 5).

\section{Perceived response in intra-dyadic positive experiences ( $H 2 d$ )}

Fit parameters indicated a good model fit $\left(\chi^{2}=3.2\right.$; $d=2 ; p=.21 ; \chi^{2} / d f=1.6 ;$ CFI $=0.997 ;$ TLI $=.990 ;$
RMSEA $=.052)$. Finally, we predicted that perceived responses to intra-dyadic capitalization would mediate the association between intra-dyadic positive experiences and relationship satisfaction. We found a significant indirect effect for women $(\beta=.29, p=.000)$ but not for men $(\beta=.01, p=0.789$, see Table 5$)$.

\section{Discussion}

Negative and positive extra-dyadic experiences (e.g. job stress, success at work) and events within the close relationship form the context of couples' everyday experiences. Studies have repeatedly shown that external experiences can spill over into the intimate relationship (e.g. Edwards \& Rothbard, 2000; Repetti, 1989). Although it is reasonable to assume that positive and negative spillover mechanisms are not independent of each other, to our knowledge, no study has examined both processes simultaneously.

In addition, previous studies have shown that one partner's response to the other's experience of a negative event can have a great impact on the spillover process (Falconier, Nussbeck, \& Bodenmann, 2013; Merz, Meuwly, Randall, \& Bodenmann, 2014). For example, a partner's supportive response after experiencing extra-dyadic stress not only has a major impact on reducing stress but is also associated with more closeness and relationship satisfaction (Bodenmann, 2000). Based on this idea, we assumed that the partner's corresponding response might act as a mediator for each of the four experiences. Testing this assumption was another aim of this study. 
Table 5. Direct effects, total direct effects, and indirect effects of the path analytical multigroup mediation model for the mediation models of negative experiences and relationship satisfaction (Hypotheses 2c \& 2d).

\begin{tabular}{|c|c|c|c|c|c|}
\hline & Lower $2.5 \%$ & Estimate & Upper $2.5 \%$ & s.e. & $p$ \\
\hline \multicolumn{6}{|c|}{ Extra-dyadic positive experiences } \\
\hline \multicolumn{6}{|c|}{ Direct effects } \\
\hline $\mathrm{M} \& \mathrm{~W}: \mathrm{EP} \rightarrow \mathrm{PrEP}$ & 0.039 & 0.164 & 0.289 & 0.064 & 0.010 \\
\hline $\mathrm{M} \& \mathrm{~W}: \mathrm{PrEP} \rightarrow \mathrm{IP}$ & 0.452 & 0.555 & 0.659 & 0.053 & 0.000 \\
\hline $\mathrm{M} \& \mathrm{~W}: \mathrm{EP} \rightarrow \mathrm{IP}$ & 0.088 & 0.207 & 0.326 & 0.061 & 0.001 \\
\hline M\&W: Total direct effect & 0.163 & 0.298 & 0.434 & 0.069 & 0.000 \\
\hline \multicolumn{6}{|l|}{ Indirect effects } \\
\hline M\&W: Indirect effect & 0.020 & 0.091 & 0.162 & 0.036 & 0.012 \\
\hline \multicolumn{6}{|c|}{ Intra-dyadic positive experiences } \\
\hline \multicolumn{6}{|c|}{ Direct effects } \\
\hline M\&W: IP $\rightarrow$ PrIP & 0.360 & 0.429 & 0.499 & 0.035 & 0.000 \\
\hline M: PrIP $\rightarrow$ RS & -0.201 & 0.032 & 0.264 & 0.119 & 0.789 \\
\hline $\mathrm{W}: \operatorname{PrIP} \rightarrow \mathrm{RS}$ & 0.462 & 0.671 & 0.880 & 0.107 & 0.000 \\
\hline $\mathrm{M} \& \mathrm{~W}: \mathrm{IP} \rightarrow \mathrm{RS}$ & 0.622 & 0.752 & 0.883 & 0.066 & 0.000 \\
\hline M: Total direct effect & 0.634 & 0.766 & 0.898 & 0.067 & 0.000 \\
\hline W: Total direct effect & 0.927 & 1.040 & 1.154 & 0.058 & 0.000 \\
\hline \multicolumn{6}{|l|}{ Indirect effects } \\
\hline M: Indirect effect & -0.086 & 0.014 & 0.114 & 0.051 & 0.789 \\
\hline W: Indirect effect & 0.187 & 0.288 & 0.389 & 0.051 & 0.000 \\
\hline
\end{tabular}

Note: $\mathrm{M}=$ men; $\mathrm{W}=$ women; $\mathrm{M} \& \mathrm{~W}=$ men and women; $\mathrm{EP}=$ extra-dyadic positive experience; PrPN = partner response to extra-dyadic positive experience; IP = intra-dyadic positive experience; PrIP = partner response to intra-dyadic positive experience; RS = relationship satisfaction; lower and upper $2.5 \%$ indicate the boundaries of the $95 \%$ confidence interval; s.e. $=$ standard error; $p=$ significance level. Unstandardized results are depicted.

\section{Positive and negative intra-dyadic experiences as mediators}

First we assumed that intra-dyadic experiences would mediate the link between extra-dyadic experiences and relationship satisfaction. The results show that both intradyadic negative and positive experiences significantly mediate the association between negative extra-dyadic experiences and relationship satisfaction. This is in line with the findings of Bodenmann et al. (2007) and Ledermann, Bodenmann, Rudaz, and Bradbury (2010), showing that extra-dyadic negative experiences do not have a strong direct effect on relationship satisfaction, but instead increase intra-dyadic negative experiences (e.g. conflicts), which in turn reduce the level of relationship satisfaction. Additionally, the effects of extra-dyadic negative experiences also reduce positive intra-dyadic experiences, which affect relationship satisfaction negatively as well. These findings support the stress-divorce model (Bodenmann et al., 2007), which postulates that extra-dyadic stress not only increases the likelihood of negative couple interactions but also reduces positive aspects such as shared time, self-disclosure, or sexuality.

In addition, the results also show that both intradyadic negative and positive experiences mediate the link between positive extra-dyadic experiences and relationship satisfaction - but just for women. For men, we found no significant mediation effect (i.e. positive intradyadic experience was marginally significant; $p=.052$ ). This finding is unexpected for two reasons. Results for men suggest that 'bad is stronger than good' (Baumeister, Bratslavsky, Finkenauer, \& Vohs, 2001) and mainly negative extra-dyadic experiences perpetuate the couple system in a negative way. However, this is clearly not the case for women. For women, positive extra-dyadic experiences affected their relationship satisfaction by positive and negative intra-dyadic experiences. These findings may suggest that women are often not pleased by their partner's reactions on positive experiences they made, which may lead to negative interactions due to deception and anger. This has been addressed in the support gap hypothesis (Belle, 1983). Furthermore, sharing positive experiences does not automatically lead to positive interactions but may find insufficient resonance in the partner, elicit envy, or just not evoke enough common joy. Often, women perceive men's reactions as not matching their needs (Xu \& Burleson, 2004). Women self-disclose more often and seem more sensitive to these processes, which may explain the findings for women (Jensen, Rauer, \& Volling, 2013; Verhofstadt, Buysse, \& Ickes, 2007).

Overall, we also find that women report significantly higher levels of negative and positive extra-dyadic experiences and positive intra-dyadic experiences than men. Thus, we assume that women could be more susceptible when experiencing a positive event. In addition, we find a significant correlation between negative and positive extra-dyadic experiences for women, but not for men. Although there might be reasons why negative and 
positive events are or are not correlated, it is stunning to find a clear gender difference on such a basic level. This result indicates that for women, negative and positive extra-dyadic events are related, whereas they are not for men. Again, this finding may be in line with previous results showing that women are generally more emotional and tend more often toward self-disclosure (Dindia, 2002; Tannen, 1990).

\section{Perceived partner response as mediator}

We further predicted that the perceived partner response is a mediator between extra- and intra-dyadic experiences and also between intra-dyadic experiences and relationship satisfaction (see Figure 2). Overall, we tested whether the four different perceived partner responses would mediate the effect of the four corresponding different events on couple outcomes in order to illustrate how crucial the partner's response to the four different experiences is.

With one exception, we found that the perceived partner response significantly mediates all experiences for both genders. More specifically, when testing for negative experiences, perceived partner responses mediate the association between negative extra- and negative intra-dyadic experiences, supporting the assumption of the SystemicTransactional Model that the partner's support and dyadic coping behavior in times of need affects relationship outcomes and supports prior findings (Hilpert et al., 2013). Furthermore, the results provide evidence that perceived responsive behavior mediates the association between negative intra-dyadic experiences and relationship satisfaction.

As one of the main focuses of the current article, we aimed to examine mechanisms (i.e. mediation) in positive experiences. First, results indicate that the perceived partner response (i.e. capitalization response) mediates the link between positive extra-dyadic and intra-dyadic positive experiences. This finding reflects a similar picture as has been shown for the negative spillover effects. Positive extra-dyadic experiences spill over via the partner response and affect positive intra-dyadic experiences, i.e. increase the intra-dyadic positive behavior. Thus, the positive extra-dyadic experience and the partner's response to this do not simply increase the level of happiness or satisfaction as shown in a few other studies (Gable et al., 2004), but actually seem to affect the positive interactions within the relationship. This finding is in line with the prediction of the intimacy process model (Reis \& Shaver, 1988) that the partner's response to a shared crucial experience affects the couple's interactions, and, in the long term, relationship outcomes. Finally, we extended the concept of capitalization to intradyadic experiences. This concept differs from the capitalization concept described thus far in the literature (e.g. Gable et al., 2004, 2012; Gable \& Reis, 2010) in the way that couples discuss and validate the experience they had together and, therefore, the partner is aware of the content.

However, it is still reasonable to assume that capitalization on internal events and the partner's response might also be associated with relationship satisfaction. We found evidence that the association between intradyadic positive experiences and relationship satisfaction is mediated by the partner's responsive behavior for women, but not for men. For women, the partner's response seems to have a direct effect on their relationship satisfaction, whereas this effect could not be found for men. It seems that for women, the partner's response appears to be an explanatory mechanism linking together how extra-dyadic experiences predict relationship satisfaction. The more positive and supportive the response of the partner is on the reflections about the positive interaction with the other partner, the more women feel that the relationship is satisfying. This finding can be understood based on the intimacy process model. The question is, however, why this seems not to be the case for men. In general, we find that the correlations between intra-dyadic positive experience and partner's response are similar for women and men $\left(r_{\text {women }}=.56 ; r_{\text {men }}=.58\right)$, but no mediating effect for men could be reported. One explanation could be that men do not base their relationship satisfaction on the social aspect of talking with their partner about situations they appreciated and getting a response about it from the partner, but rather on the positive intra-dyadic experience itself. As Burnett (1984, 1987) discovered, men were less interested in talking about relationships than women. Consistent with that, husband's communication about the relationship was positively associated for women but not vice versa (Acitelli, 1992; Kalin \& Lloyd, 1985; Murstein \& Williams, 1985; Noller \& Venardos, 1986; White, Speisman, Jackson, Bartis, \& Costos, 1986). Gottman and Krokoff (1989) also conclude that the impact of husband's responsiveness might be more meaningful since women place more importance on relationship maintenance behaviors. All these reasons might contribute to the gender differences reported in our study. However, it does not completely explain why we find these results for positive events only.

In summary, these findings point to a variety of clinical implications. First, results show once again the importance of training couples in providing each other with support and being responsive to the partner's needs. The detrimental influence of extra-dyadic stressors can be reduced when the couples have the appropriate communication skills and are able to recall them in times of need in order to help each other. Second, relationship education programs (e.g. Bodenmann, Hilpert, Nussbeck, \& Bradbury, 2014) already train couples in dealing with negative extra-dyadic 
experiences, but they rarely focus on the positive aspects and do not foster the sharing of good moments with the partner together (internal capitalization), which could be implemented in future relationship education programs. Finally, if couples learn about the impact of the exchange of positive behaviors and how powerful their perceived responses are to their partner's disclosure, they may learn how to support and encourage one another in a new way.

\section{Strengths and limitations}

Besides the study's strength of simultaneously examining positive and negative everyday life experiences, this current study has several limitations. First, the data is based on self-report, which may inflict personal bias. Second, due to the online questionnaire format, the study is only cross-sectional and we would gain more information by using longitudinal data. Third, crosssectional data do not allow drawing causal inferences. Fourth, the sample is not evenly distributed for men and women, and this might have led to biased results.

\section{Disclosure statement}

No potential conflict of interest was reported by the authors.

\section{References}

Acitelli, L. K. (1992). Gender differences in relationship awareness and marital satisfaction among young married couples. Personality and Social Psychology Bulletin, 18, 102-110. doi:10.1177/0146167292181015

Baumeister, R. F., Bratslavsky, E., Finkenauer, C., \& Vohs, K. D. (2001). Bad is stronger than good. Review of General Psychology, 5, 323-370. doi:10.1037/1089-2680.5.4.323

Belle, D. E. (1983). The impact of poverty on social networks and supports. Marriage \& Family Review, 5, 89-103. doi:10.1300/J002v05n04_06

Bodenmann, G. (1997). Dyadic coping - a systemic-transactional view of stress and coping among couples: Theory and empirical findings. European Review of Applied Psychology, 47, 137-140.

Bodenmann, G. (2000). Stress und Coping bei Paaren [Stress and coping in couples]. Göttingen, Germany: Hogrefe.

Bodenmann, G. (2005). Dyadic coping and its significance for marital functioning. In T. Revenson, K. Kayser, \& G. Bodenmann (Eds.), Couples coping with stress: Emerging perspectives on dyadic coping (pp. 33-50). Washington, DC: American Psychological Association.

Bodenmann, G. (2008). Dyadisches coping inventar. Manual. Bern: Hans Huber.

Bodenmann, G., \& Cina, A. (2006). Stress and coping among stable-satisfied, stable-distressed and separated/divorced Swiss couples: A 5-year prospective longitudinal study. Journal of Divorce \& Remarriage, 44, 71-89. doi:10.1300/ J087v44n01_04

Bodenmann, G., Hilpert, P., Nussbeck, F. W., \& Bradbury, T. N. (2014). Enhancement of couples' communication and dyadic coping by a self-directed approach: A randomized controlled trial. Journal of Consulting and Clinical Psychology, 82, 580-591. doi:10.1037/a0036356
Bodenmann, G., Ledermann, T., \& Bradbury, T. N. (2007). Stress, sex, and satisfaction in marriage. Personal Relationships, 14, 551-569. doi:10.1111/j.1475-6811.2007.00171.x

Bodenmann, G., Meuwly, N., Bradbury, T., Gmelch, S., \& Ledermann, T. (2010). Stress and verbal aggression in intimate relationships: Moderating effects of trait anger and dyadic coping. Journal of Social and Personal Relationships, 27, 408-424. doi:10.1177/0265407510361616

Bodenmann, G., Pihet, S., \& Kayser, K. (2006). The relationship between dyadic coping, marital quality and well-being: A 2year longitudinal study. Journal of Family Psychology, 20, 485-493. doi:10.1037/0893-3200.20.3.485

Bolger, N., DeLongis, A., Kessler, R. C., \& Wethington, E. (1989). The contagion of stress across multiple roles. Journal of Marriage and the Family, 51, 175-183. doi:10.2307/352378

Burnett, R. (Ed.). (1984). Thinking and communicating about personal relationships: Some sex differences. Paper presented at the second International Conference on Personal Relationships, Madison, WI.

Burnett, R. (1987). Reflection in personal relationships. In R. Burnett, P. McGhee, \& D. C. Clarke (Eds.), Accounting for relationships: Explanation, representation and knowledge (pp. 74-93). London: Methuen.

Caughlin, J. P., \& Huston, T. L. (2010). The flourishing literature on flourishing relationships. Journal of Family Theory \& Review, 2, 25-35. doi:10.1111/j.1756-2589.2010.00034.x

Clark, M. S., \& Monin, J. K. (2006). Giving and receiving communal responsiveness as love. In R. J. Sternberg \& K. Weis (Eds.), The new psychology of love (pp. 200-221). New Haven, CT: Yale University Press.

Cramer, D. (2006). How a supportive partner may increase relationship satisfaction. British Journal of Guidance \& Counselling, 34, 117-131. doi:10.1080/ 03069880500483141

Dindia, K. (2002). Self-disclosure research: Knowledge through meta-analysis. In M. Allen, R. W. Preiss, B. M. Gayle, \& N. A. Burrell (Eds.), Interpersonal communication research: Advances through meta-analysis (pp. 169-185). Hillsdale, NJ: Lawrence Erlbaum Associates.

Edwards, J. R., \& Rothbard, N. P. (2000). Mechanisms linking work and family: Clarifying the relationship between work and family constructs. Academy of Management Review, 25, 178-199. doi:10.5465/AMR.2000.2791609

Falconier, M. K., Nussbeck, F., \& Bodenmann, G. (2013). Dyadic coping in Latino couples: Validity of the Spanish version of the dyadic coping inventory. Anxiety, Stress \& Coping, 26, 447-466. doi:10.1080/10615806.2012.699045

Funk, J. L., \& Rogge, R. D. (2007). Testing the ruler with item response theory: Increasing precision of measurement for relationship satisfaction with the couples satisfaction index. Journal of Family Psychology, 21, 572-583. doi:10.1037/ 0893-3200.21.4.572

Gable, S. L., Gosnell, C. L., Maisel, N. C., \& Strachman, A. (2012). Safely testing the alarm: Close others' responses to personal positive events. Journal of Personality and Social Psychology, 103, 963-981. doi:10.1037/a0029488

Gable, S. L., \& Reis, H. T. (2006). Intimacy and the self: An iterative model of the self and close relationships. In P. Noller \& J. Feeney (Eds.), Close relationships: Functions forms, and processes (pp. 211-225). Hove England: Psychology Press.

Gable, S. L., \& Reis, H. T. (2010). Good news! Capitalizing on positive events in an interpersonal context. Advances in Experimental Social Psychology, 42, 195-257. doi:10.1016/ S0065-2601(10)42004-3 
Gable, S. L., Reis, H. T., Impett, E. A., \& Asher, E. R. (2004). What do you do when things go right? The intrapersonal and interpersonal benefits of sharing positive events. Journal of Personality and Social Psychology, 87, 228-245. doi:10.1037/0022-3514.87.2.228

Gottman, J. M., \& Krokoff, L. J. (1989). Marital interaction and satisfaction: A longitudinal view. Journal of Consulting and Clinical Psychology, 57, 47-52. doi:10.1037/0022006X.57.1.47

Graber, E. C., Laurenceau, J.-P., Miga, E., Chango, J., \& Coan, J. (2011). Conflict and love: Predicting newlywed marital outcomes from two interaction contexts. Journal of Family Psychology, 25, 541-550. doi:10.1037/a0024507

Greenhaus, J. H., \& Powell, G. N. (2006). When work and family are allies: A theory of work-family enrichment. The Academy of Management Review, 31, 72-92. doi:10.5465/ AMR.2006.19379625

Hanson, G. C., Hammer, L. B., \& Colton, C. L. (2006). Development and validation of a multidimensional scale of perceived work-family positive spillover. Journal of Occupational Health Psychology, 11, 249-265. doi:10.1037/1076-8998.11.3.249

Herzberg, P. Y. (2013). Coping in relationships: The interplay between individual and dyadic coping and their effects on relationship satisfaction. Anxiety, Stress, \& Coping: An International Journal, 26, 136-153. doi:10.1080/ 10615806.2012.655726

Hilpert, P., Bodenmann, G., Nussbeck, F. W., \& Bradbury, T. N. (2013). Predicting relationship satisfaction in distressed and non-distressed couples based on a stratified sample: A matter of conflict, positivity, or support?. Family Science, 4, 110 120. doi:10.1080/19424620.2013.830633

Jensen, J., Rauer, A. J., \& Volling, B. L. (2013). A dyadic view of support in marriage: The critical role of men's support provision. Sex Roles, 68, 427-438. doi:10.1007/s11199-0120256-x

Kalin, R., \& Lloyd, C. A. (1985). Sex role identity, sex-role ideology and marital adjustment. International Journal of Women's Studies, 8, 32-39.

Karney, B. R., Story, L. B., \& Bradbury, T. N. (2005). Marriages in context: Interactions between chronic and acute stress among newlyweds. In T. A. Revenson, K. Kayser, \& G. Bodenmann (Eds.), Couples coping with stress: Emerging perspectives on dyadic coping (pp. 13-32). Washington, DC: American Psychological Association.

King, D. B., \& DeLongis, A. (2014). When couples disconnect: Rumination and withdrawal as maladaptive responses to everyday stress. Journal of Family Psychology, 28, 460 469. doi: $10.1037 / \mathrm{a} 0037160$

Kurdeck, L. A. (1994). Conflict resolution styles in gay, lesbian, heterosexual nonparent, and heterosexual parent couples. Journal of Marriage and the Family, 56, 705-722. doi: $10.2307 / 352880$

Langston, C. A. (1994). Capitalizing on and coping with dailylife events: Expressive responses to positive events. Journal of Personality and Social Psychology, 67, 1112-1125. doi:10.1037/0022-3514.67.6.1112

Ledermann, T., Bodenmann, G., Rudaz, M., \& Bradbury, T. N. (2010). Stress, communication, and marital quality in couples. Family Relations, 59, 195-206. doi:10.1111/j.17413729.2010.00595.x

Maisel, N. C., Gable, S. L., \& Strachman, A. (2008). Responsive behaviors in good times and in bad.
Personal Relationships, 15, 317-338. doi:10.1111/j.14756811.2008.00201.x

Marchand, J. F. (2004). Husbands' and wives' marital quality: The role of adult attachment orientations, depressive symptoms, and conflict resolution behaviors. Attachment \& Human Development, 6, 99-112. doi:10.1080/ 14616730310001659575

Merz, C. A., Meuwly, N., Randall, A. K., \& Bodenmann, G. (2014). Engaging in dyadic coping: Buffering the impact of everyday stress on prospective relationship satisfaction. Family Science, 5, 30-37. doi:10.1080/ 19424620.2014.927385

Mikulincer, M., \& Shaver, P. R. (2003). The attachment behavioral system in adulthood: Activation, psychodynamics, and interpersonal processes. In M. P. Zanna (Ed.), Advances in experimental social psychology (Vol. 35, pp. 53-152). New York, NY: Academic Press.

Miner, A. G., Glomb, T. M., \& Hulin, C. (2005). Experience sampling mood and its correlates at work. Journal of Occupational and Organizational Psychology, 78, 171193. doi:10.1348/096317905X40105

Murstein, B. I., \& Williams, P. D. (1985). Assortative matching for sex-role and marriage adjustment. Personality and Individual Differences, 6, 195-201. doi:10.1016/0191-8869 (85)90109-6

Noller, P., \& Venardos, C. (1986). Communication awareness in married couples. Journal of Social and Personal Relationships, 3, 31-42. doi:10.1177/0265407586031003

Papp, L. M., \& Witt, N. L. (2010). Romantic partners' individual coping strategies and dyadic coping: Implications for relationship functioning. Journal of Family Psychology, 24, 551-559. doi:10.1037/a0020836

Randall, A. K., \& Bodenmann, G. (2009). The role of stress on close relationships and marital satisfaction. Clinical Psychology Review, 29, 105-115. doi:10.1016/j. cpr.2008.10.004

Reis, H. T. (2012). Perceived partner responsiveness as an organizing theme for the study of relationships and well-being. In L. Campbell \& T. J. Loving (Eds.), Interdisciplinary research on close relationships: The case for integration (pp. 27-52). Washington, DC: American Psychological Association.

Reis, H. T., \& Shaver, P. (1988). Intimacy as an interpersonal process. In S. Duck, D. F. Hay, S. E. Hobfoll, W. Ickes, \& B. M. Montgomery (Eds.), Handbook of personal relationships: Theory, research and interventions (pp. 367-389). Oxford, England: John Wiley \& Sons.

Repetti, R. L. (1989). Effects of daily workload on subsequent behavior during marital interaction: The roles of social withdrawal and spouse support. Journal of Personality and Social Psychology, 57, 651-659. doi:10.1037/00223514.57.4.651

Rosseel, Y. (2012). lavaan: An R package for structural equation modeling. Journal of Statistical Software, 48, 1-36. Retrieved from http://www.jstatsoft.org/v48/i02/

Schermelleh-Engel, K., Moosbrugger, H., \& Müller, H. (2003). Evaluating the fit of structural equation models: Tests of significance and descriptive goodness-of-fit measures. Methods of Psychological Research, 8, 23-74.

Sierau, S., \& Herzberg, P. Y. (2012). Conflict resolution as a dyadic mediator: Considering the partner perspective on conflict resolution. European Journal of Personality, 26, 221-232. doi:10.1002/per.828 
Stephens, M. A. P., Franks, M. M., \& Atienza, A. A. (1997). Where two roles intersect: Spillover between parent care and employment. Psychology and Aging, 12, 30-37. doi:10.1037/0882-7974.12.1.30

Story, L. B., \& Repetti, R. (2006). Daily occupational stressors and marital behavior. Journal of Family Psychology, 20, 690-700. doi:10.1037/0893-3200.20.4.690

Sullivan, K. T., Pasch, L. A., Johnson, M. J., \& Bradbury, T. N. (2010). Social support, problem-solving, and the longitudinal course of newlywed marriage. Journal of Personality and Social Psychology, 98, 631-644. doi: $10.1037 / \mathrm{a} 0017578$

Tannen, D. (1990). You just don't understand: Women and men in conversation. New York, NY: Harper Collins.

Verhofstadt, L. L., Buysse, A., \& Ickes, W. (2007). Social support in couples: An examination of gender differences using self-report and observational methods. Sex Roles, 57, 267282. doi:10.1007/s11199-007-9257-6

Wayne, J. H., Musisca, N., \& Fleeson, W. (2004). Considering the role of personality in the work-family experience: Relationships of the big five to work-family conflict and facilitation. Journal of Vocational Behavior, 64, 108-130. doi:10.1016/S0001-8791(03)00035-6

White, K. M., Speisman, J. C., Jackson, D., Bartis, S., \& Costos, D. (1986). Intimacy maturity and its correlates in young married couples. Journal of Personality and Social Psychology, 50, 152-162. doi:10.1037/0022-3514.50.1.152.

$\mathrm{Xu}$, Y., \& Burleson, B. R. (2004). The association of experienced spousal support with marital satisfaction: Evaluating the moderating effects of sex, ethnic culture, and type of support. The Journal of Family Communication, 4, 123145. doi:10.1207/s15327698jfc0402_3 